\title{
TISO ADJUSTABLE FILTER WITH CONTROLLABLE CONTROLLED-GAIN VOLTAGE DIFFERENCING CURRENT CONVEYOR
}

\author{
Jan Jerabek ${ }^{*}$ - Roman Sotner ${ }^{* *}$ - Kamil Vrba ${ }^{*}$
}

\begin{abstract}
The main aim of this paper is to present solution of triple-input single-output (TISO) filter with independently adjustable pole frequency, quality factor, bandwidth and also gain. Filter is universal, operates in current mode and includes only one active element - the so-called Controlled-Gain Voltage Differencing Current Conveyor (CG-VDCC) with two controllable parameters: transconductance $\left(g_{m}\right)$ and gain of output currents $\left(B_{X}\right)$. Implementation of CG-VDCC element in $0.18 \mu \mathrm{m}$ CMOS technology is also included and this model is used in proposed filter simulations.

K e y w or d s: current mode, SITO filter, universal filter, CG-VDCC
\end{abstract}

\section{INTRODUCTION}

There have been many controllable active elements reported in recent works, brief summarization is given in [1]. Some active elements which have two externally controllable (by bias voltage or current) parameters have been already published. Typical examples of active elements with two-parameter control are modifications of the current differencing transconductance amplifier (CDTA) [2], where $R_{X}$ and $g_{m}$ control is implemented by DC bias currents $[3,4]$. Several active elements, based on transconductance section (OTA) $[1,5]$ and current conveyor of second generation (CCII) [6,7], have been also proposed. For example, current conveyor transconductance amplifier (CCTA) [8] also utilizes independent $R_{X}$ and $g_{m}$ control in some of its variants, for example [9]. Modification of CCTA in [10] employs current gain control, where current conveyor with adjustable gain from $\mathrm{X}$ to $\mathrm{Z}$ terminal was used. Controllable current gain in frame of current conveyor $[11,12]$ seems to be an interesting and valuable advantage [13-21].

Proposed novel active element provides useful controllable features. The so-called CG-VDCC consists of OTA and CCII elements (note that CCTA consists of the same active elements, but in reverse order). Our solution presented in this paper provides electronic control of gm and of three current gains (each of them independently), therefore four parameters are controllable. As obvious from the presented transistor structure, $R_{X}$ could also be controlled but it is not required in our case. This approach allows construction of very simple applications with minimum passive elements.

Active elements with more than one controllable parameter are very useful. They usually allow electronic control of more than one parameter of final filtering solution. In case of filter, it is pole frequency, quality factor, bandwidth and pass-band or stop-band gain [22]. Only one (more complex) active element is sufficient in many cases.

We provided a study of several universal filtering solutions and found following drawbacks concerning mainly lack of electronically controllable features of proposed applications:

- Not all parameters of the filter are adjustable independently and electronically [23],

- Too many active or passive elements are required $[24,25]$,

- Not all passive elements are grounded or outputs are taken from passive elements and therefore additional buffering is required [26, 27],

- Copies or inversions of input current are required (in case of presented filter, copies are required only for band-stop and all-pass filtering functions) [28],

- Absorption of parasitic input resistance is not possible $[27,29]$.

This paper is divided to two main parts. The first part deals with explanation of CG-VDCC behavior which is supported by simulations with CMOS model of proposed element. The second part discusses application of CGVDCC in universal current-mode filter.

\section{VOLTAGE DIFFERENCING CURRENT CONVEYOR}

CG-VDCC element consists of transconductance section with electronically adjustable transconductance $\left(g_{m}\right)$ and electronically controllable current conveyor of second generation with several outputs with electronically

\footnotetext{
* Department of Telecommunications, ${ }^{* *}$ Department of Radio Electronics, Brno University of Technology, Technická 12,616 00 Brno, Czech Republic, jerabekj@feec.vutbr.cz
} 

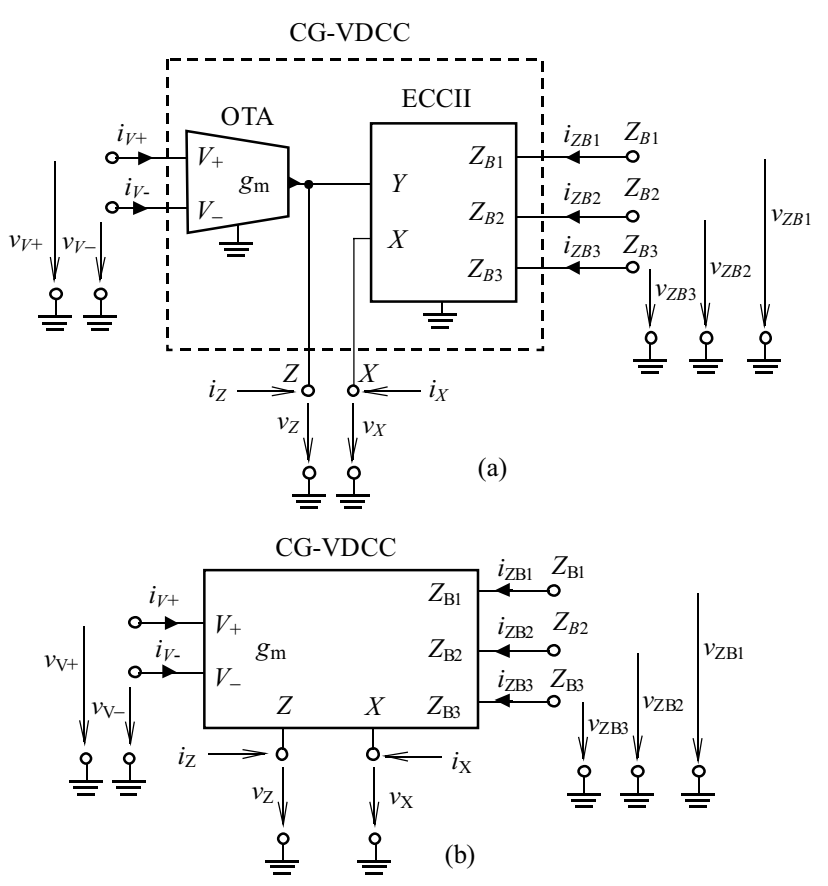

Fig. 1. Controlled-Gain Voltage Differencing Current Conveyor (CG-VDCC) with three controllable gains, (a) - basic structure, (b) - schematic symbol

adjustable current gain from $X$ terminal to $Z_{\mathrm{B} 1-3}$ terminals. The key feature of our solution is that current gains can be controlled mutually independently. Basic structure of CG-VDCC active elements is shown in Fig. 1(a), schematic symbol in Fig. 1(b).

CG-VDCC has two voltage inputs $(\mathrm{V}+$ and $\mathrm{V}-$ ), auxiliary high-impedance port $Z$ (output of OTA section and voltage input of ECCII), one current input $(X)$ and in this particular case three current outputs $\left(Z_{\mathrm{B} 1-3}\right)$ with controllable current gain. Outer behavior of CG-VDCC element is described by the following matrix

$$
\left[\begin{array}{c}
I_{V+} \\
I_{V-} \\
I_{Z} \\
V_{X} \\
I_{Z B 1} \\
I_{Z B 2} \\
I_{Z B 3}
\end{array}\right]=\left[\begin{array}{ccccccc}
0 & 0 & 0 & 0 & 0 & 0 & 0 \\
0 & 0 & 0 & 0 & 0 & 0 & 0 \\
-g_{m} & g_{m} & 0 & 0 & 0 & 0 & 0 \\
0 & 0 & 1 & 0 & 0 & 0 & 0 \\
0 & 0 & 0 & B_{1} & 0 & 0 & 0 \\
0 & 0 & 0 & B_{2} & 0 & 0 & 0 \\
0 & 0 & 0 & B_{3} & 0 & 0 & 0
\end{array}\right]\left[\begin{array}{c}
V_{+} \\
V_{-} \\
V_{Z} \\
I_{X} \\
V_{Z B 1} \\
V_{Z B 2} \\
V_{Z B 3}
\end{array}\right]
$$

Basic structure from Fig. 1(a) was the starting point for the design of CMOS realization of CG-VDCC shown in Fig. 2 and Fig. 3 showing the block level structure and detailed transistor structure.

Structure has three parts (transconductor, current conveyor of second generation and adjustable current amplifier). The first part is the transconductance amplifier [5] with differential NMOS pair connected to voltage input of CMOS current conveyor. Its transconductance is controlled by $I_{\text {set_gm }}$. Multiple-Output Current Conveyor section [6] is the second part. It provides three current outputs (to_CA1, to_CA2, to_CA3) that are connected to the third section (only one of them, CA1, is shown in Fig. 3). Intrinsic resistance of X terminal of MO-CCII can be controlled by $I_{\text {setRx }}$, but it is not used in this particular case. The third section, adjustable current amplifier [30], provides independent current gain of output current (by current $\left.I_{\text {setB1-3 }}\right)$. One CA section has two outputs ( $Z_{P}$ and $Z_{N}$, which means that first output is positive and the second one is negative), but only one of them is usually used in particular solution and therefore final transistor structure could be simplified according to particular requirements. If both outputs are present, their gain is the same, only the phase is inverted. If only one of this output is to be used and it is not decided if it is positive or negative, it is noted as $Z_{B}$ ( $B$ is common sign for current gain).

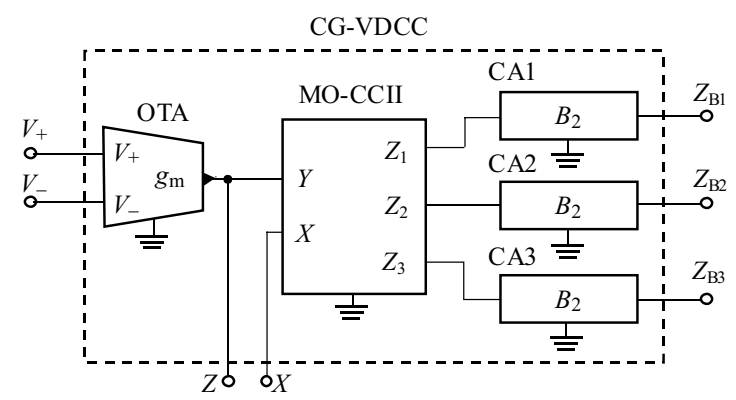

Fig. 2. Designed CMOS implementation of proposed CG-VDCC active element; block structure

Proposed CMOS model was simulated and analyzed with TSMC LO EPI $0.18 \mu \mathrm{m}$ technology [31]. Some of important simulation results of CG-VDCC model are included in this paper. Figure 4 shows DC performance of OTA section for three values of control current $I_{\text {set_gm }}$, Figure 5 shows AC performance of OTA section for the same three values of control current and Fig. 6 includes dependence of $g_{m}$ of OTA on control current.

Second group of graphs covers simulation results of MO-CCII and CA sections (connected together as a second part of a structure depicted in block diagram). Figures 7 and 8 contains $\mathrm{DC}$ and $\mathrm{AC}$ responses for three particular values of gain control current and Fig. 9 includes dependence of current gain on control current.

DC parameters of CG-VDCC element are as follows: $R_{V+}=R_{V-}>1 \mathrm{G} \Omega, R_{Z}=52 \mathrm{k} \Omega, R_{X}=450 \Omega$ $\left(I_{\text {setRX }}=150 \mu \mathrm{A}\right), R_{Z P}=R_{Z N}=58 \mathrm{k} \Omega$ (when $B=$ $1)$. Transconductance can be controlled from $255 \mu \mathrm{S}$ to $1919 \mu \mathrm{S}$ (by $I_{\text {set_gm }}=10 \mu \mathrm{A}$ to $150 \mu \mathrm{A}$ ) and current gain can be controlled from 0.36 to 3.76 (by $I_{\text {setB1-3 }}$ from $100 \mu \mathrm{A}$ to $20 \mu \mathrm{A})$. 

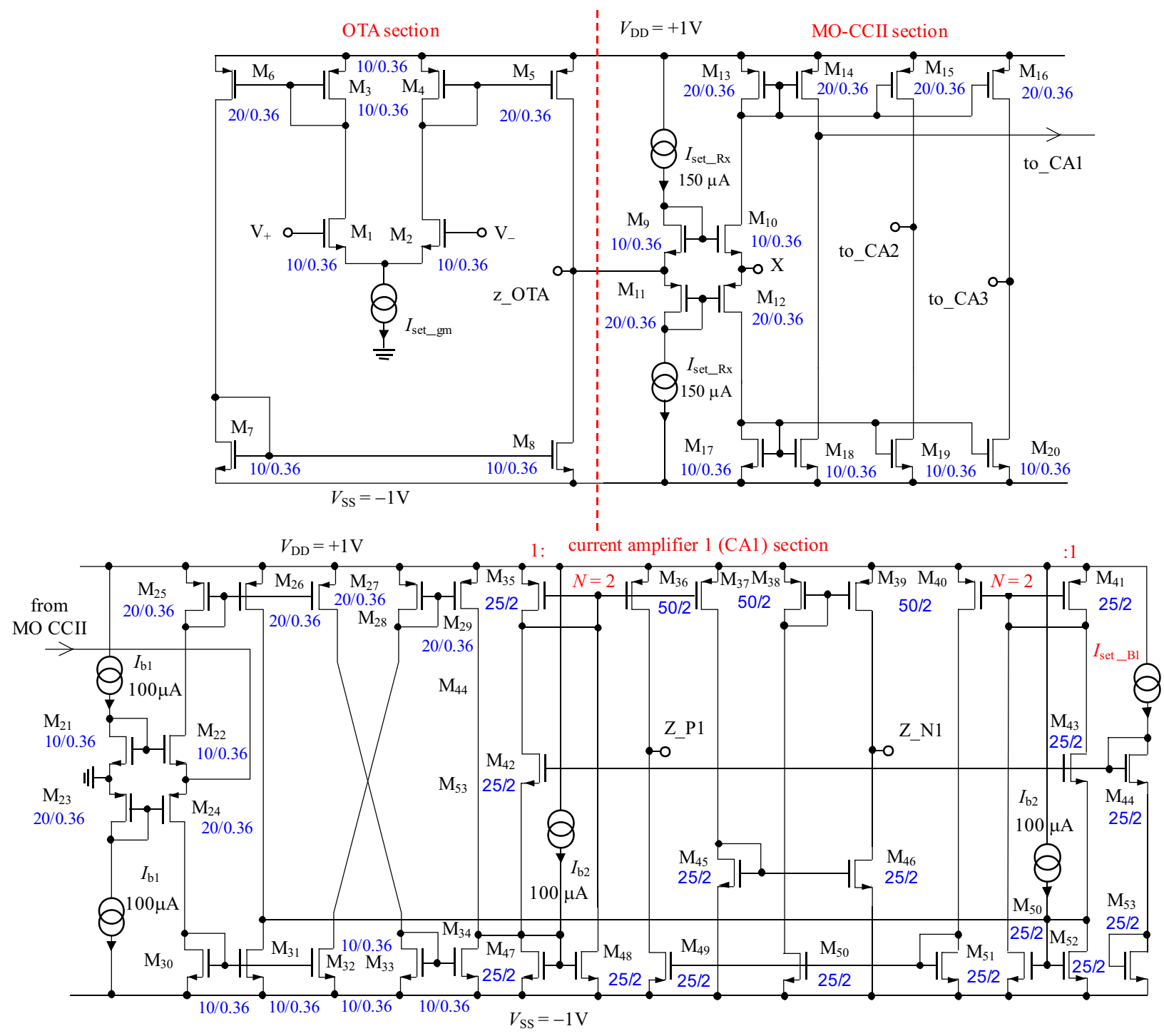

Fig. 3. Designed CMOS implementation of proposed CG-VDCC active element in a transistor level without CA2 and CA3 sections

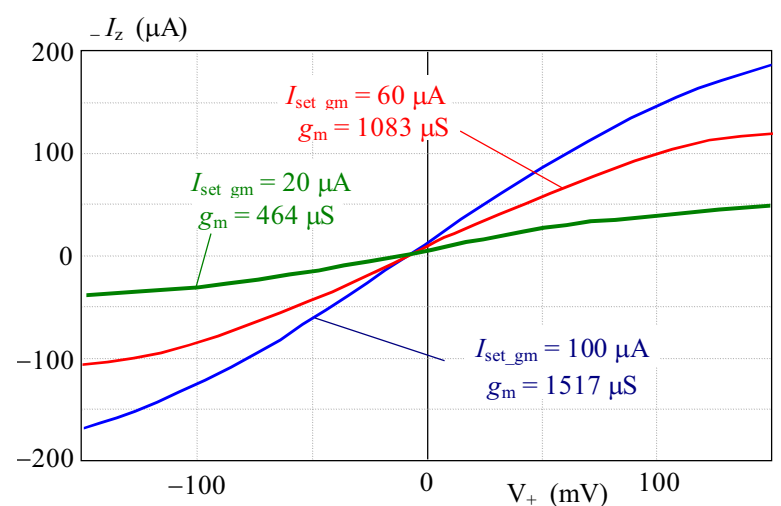

Fig. 4. OTA DC performance for selected values of control current, $V_{D D}=-V_{S S}=1 \mathrm{~V}, V-, X, Z, Z_{P B 1-3}-G N D$

\section{EXAMPLE OF FILTERING SOLUTION WITH CG-VDCC}

Proposed active element is very suitable for design of electronically controllable filters. This section presents ex-

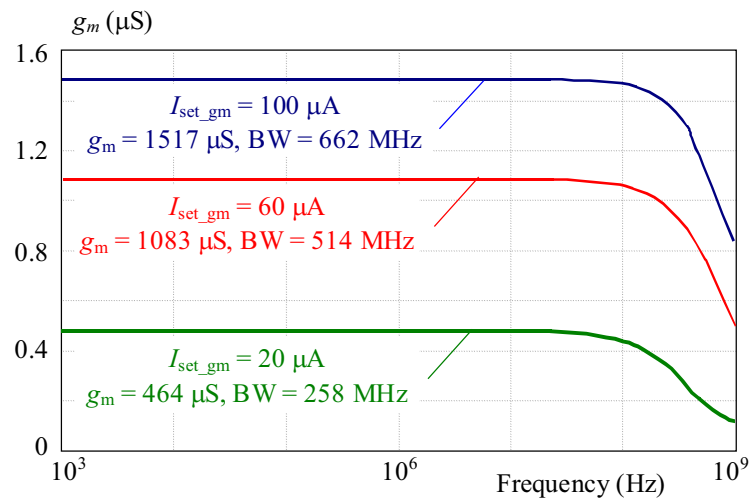

Fig. 5. OTA AC performance for selected values of control current, $V_{D D}=-V_{S S}=1 \mathrm{~V}, V-, X, Z, Z_{P B 1-3}-G N D$

ample of current-mode TISO universal controllable filter with only one CG-VDCC. Its structure is shown in Fig. 10 .

Ideal transfer functions (low pass $=\mathrm{LP}$, inverting band pass $=\mathrm{iBP}$, high pass $=\mathrm{HP}$, band stop $=\mathrm{BS}$, all pass $=$ 
140 J. Jerabek - R. Sotner - K. Vrba: TISO ADJUSTABLE FILTER WITH CONTROLLABLE CONTROLLED-GAIN VOLTAGE ...

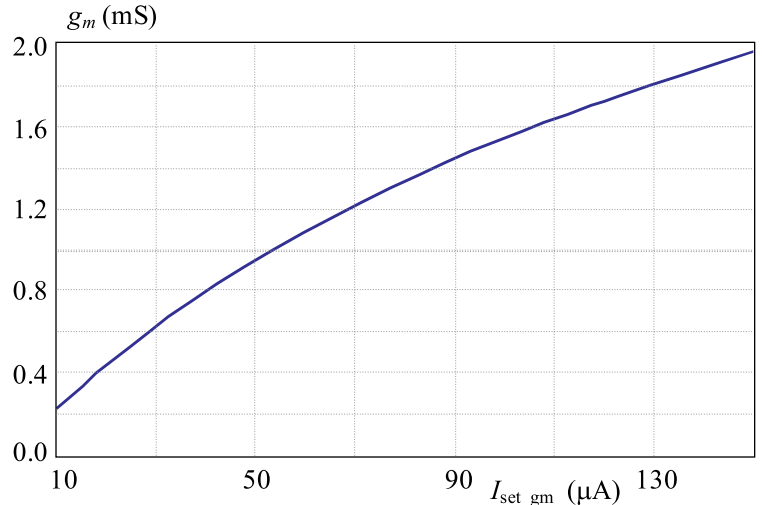

Fig. 6. Dependence of $g_{m}$ of OTA on control current, $V_{D D}=$ $-V_{S S}=1 \mathrm{~V}, V-, X, Z, Z_{P B 1-3}-G N D$

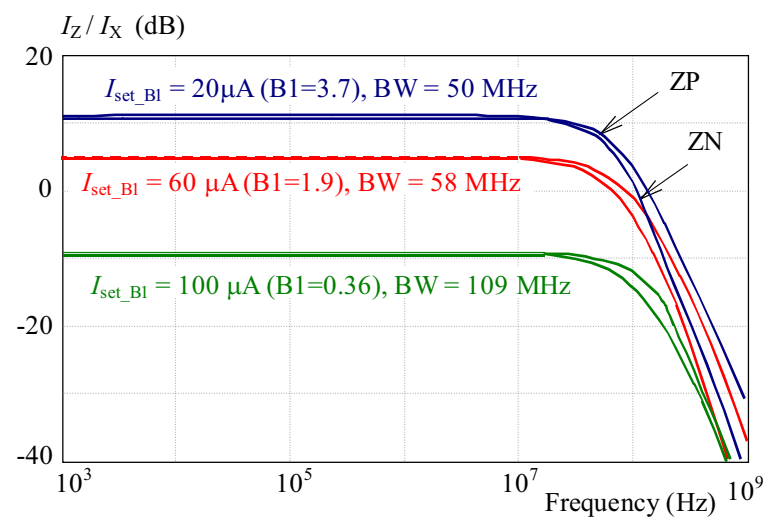

Fig. 8. MO-CCII and CA section AC performance for selected values of control current, $V_{D D}=-V_{S S}=1 \mathrm{~V}, V+, V-, Z-G N D$

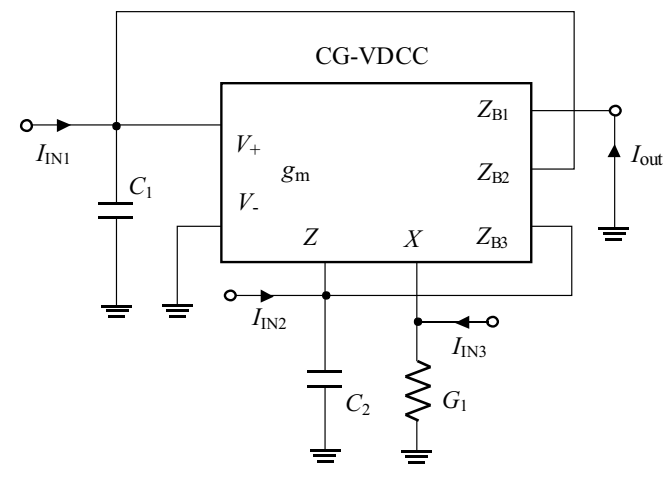

Fig. 10. Structure of TISO universal controllable filter

AP) of this filter are

$$
K_{L P}(s)=\frac{\boldsymbol{I}_{O U T}}{\boldsymbol{I}_{I N 1}}=\frac{B_{1} G_{1} g_{m}}{D(s)},
$$

if $I_{I N 1}=-I_{I N}$ and $I_{I N 2}=I_{I N 3}=0$;

$$
K_{i B P}(s)=\frac{\boldsymbol{I}_{O U T}}{\mathbf{I}_{I N 2}}=\frac{-B_{1} s C_{1} G_{1}}{D(s)},
$$

if $I_{I N 2}=I_{I N}$ and $I_{I N 1}=I_{I N 3}=0$;

$$
K_{H P}(s)=\frac{\boldsymbol{I}_{O U T}}{\boldsymbol{I}_{I N 3}}=\frac{s^{2} C_{1} C_{2} B_{1}}{D(s)},
$$

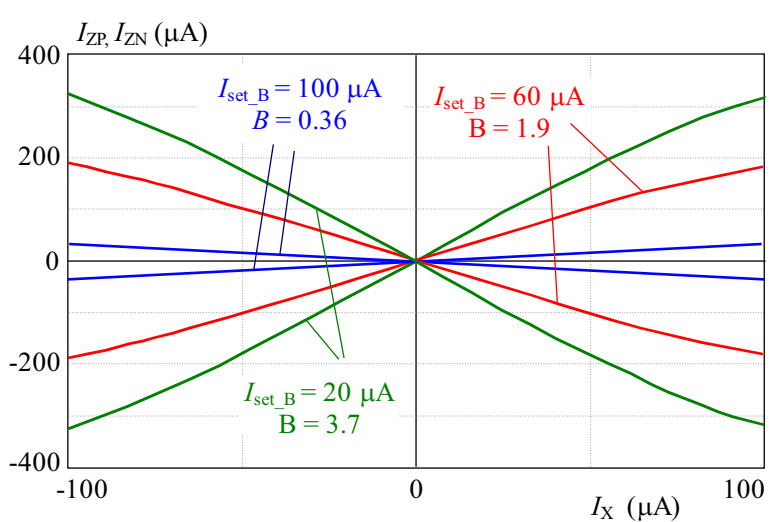

Fig. 7. MO-CCII and CA section DC performance for selected values of control current, $V_{D D}=-V_{S S}=1 \mathrm{~V}, V+, V-, Z-G N D$

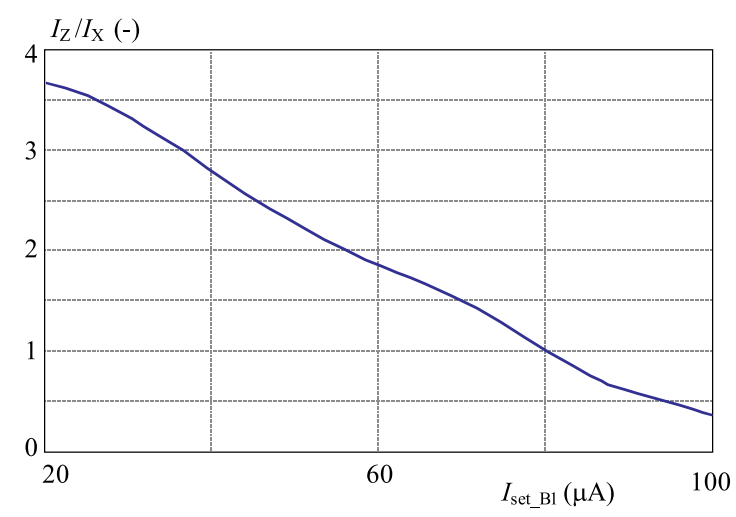

Fig. 9. Dependence of current gain of MO-CCII and CA section on control current, $V_{D D}=-V_{S S}=1 \mathrm{~V}, V+, V-, Z-G N D$

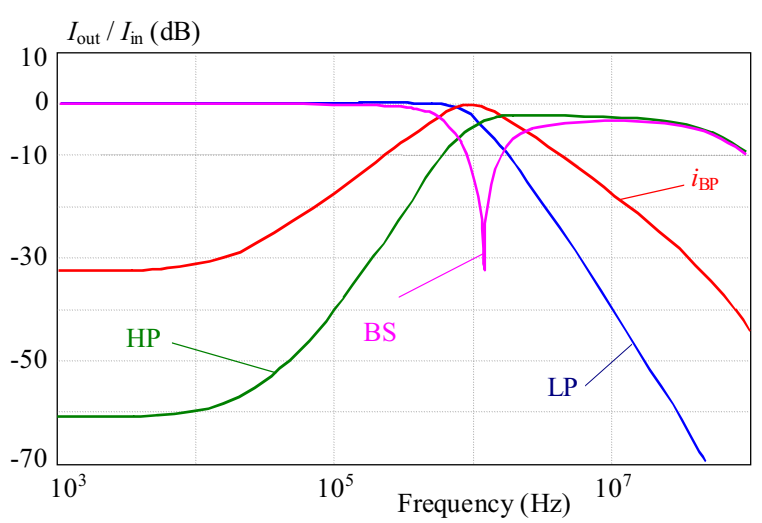

Fig. 11. Magnitude responses of $L P$, iBP, $H P$ and $B S$ functions when $B_{1}=1, B_{2}=-1, B_{3}=-1$

if $I_{I N 3}=-I_{I N}$ and $I_{I N 1}=I_{I N 2}=0$;

$$
K_{B S}(s)=\frac{\boldsymbol{I}_{O U T}}{\boldsymbol{I}_{I N 1}+\mathbf{I}_{I N 3}}=\frac{s^{2} C_{1} C_{2} B_{1}+B_{1} G_{1} g_{m}}{D(s)},
$$

if $I_{I N 1}=-I_{I N}$ and $I_{I N 3}=I_{I N}$ and $I_{I N 2}=0$;

$$
\begin{aligned}
K_{A P} & =\frac{\boldsymbol{I}_{O U T}}{\boldsymbol{I}_{I N 1}+\boldsymbol{I}_{I N 2}+\boldsymbol{I}_{I N 3}} \\
& =\frac{s^{2} C_{1} C_{2} B_{1}-B_{1} s C_{1} G_{1}+B_{1} G_{1} g_{m}}{D(s)},
\end{aligned}
$$




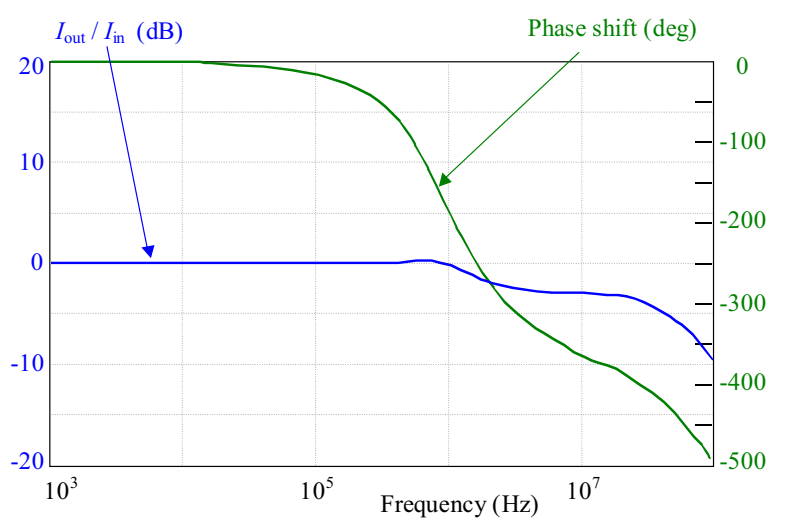

Fig. 12. Magnitude response and phase shift of AP filter when $B_{1}=1, B_{2}=-1, B_{3}=-1$

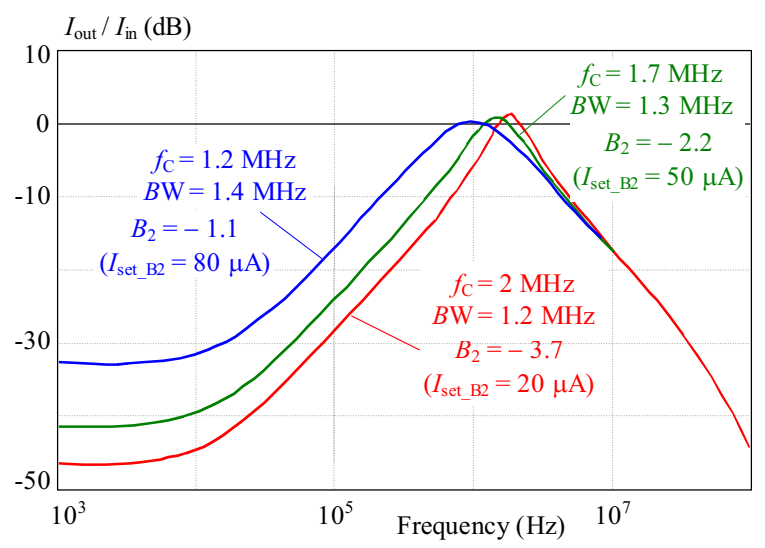

Fig. 14. Center frequency control with constant bandwidth: magnitude response of iBP for three values of gain $B_{2}$ when $B_{1}=1$, $B_{3}=-1$

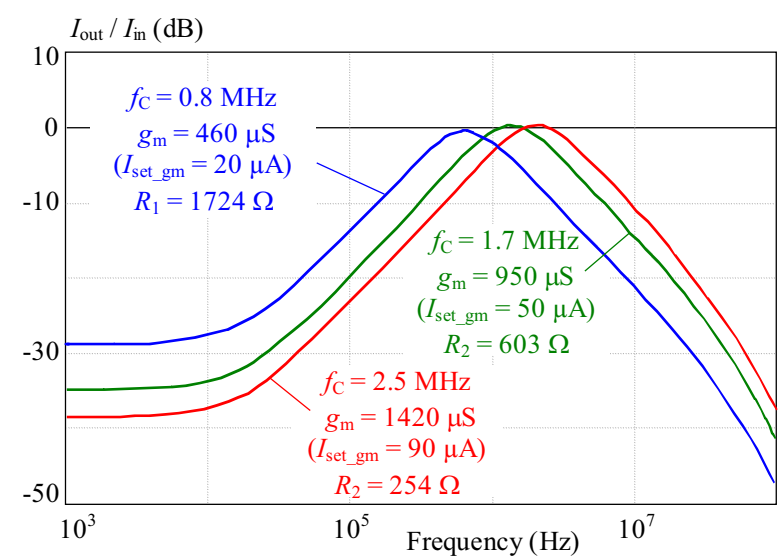

Fig. 16. Center frequency control with constant quality factor: Magnitude response of iBP for three different values of $g_{m}=G_{1}$ when $B_{1}=1, B_{2}=-1, B_{3}=-1$ and $Q=0.9$

if $I_{I N 1}=-I_{I N}$ and $I_{I N 3}=I_{I N}$ and $I_{I N 2}=I_{I N}$; where denominator is in all cases

$$
D(s)=-B_{2} G_{1} g_{m}-B_{3} s C_{1} G_{1}+s^{2} C_{1} C_{2} .
$$

It is obvious that filter is stable only for $B_{2}<0$ and $B_{3}<0$, therefore output $Z_{\mathrm{B} 2}$ and $Z_{\mathrm{B} 3}$ has to be negative. It is also obvious that two copies of input current are

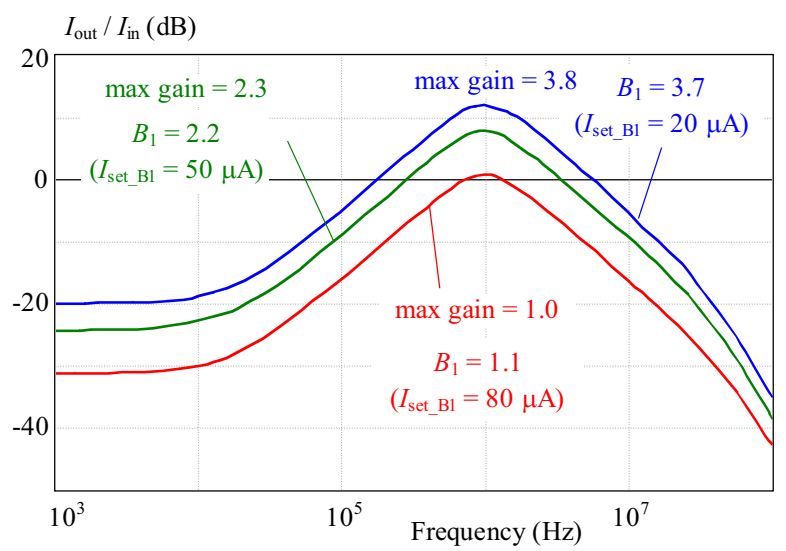

Fig. 13. Gain control: magnitude response of iBP for three different values of gain $B_{1}$ when $B_{2}=-1, B_{3}=-1$

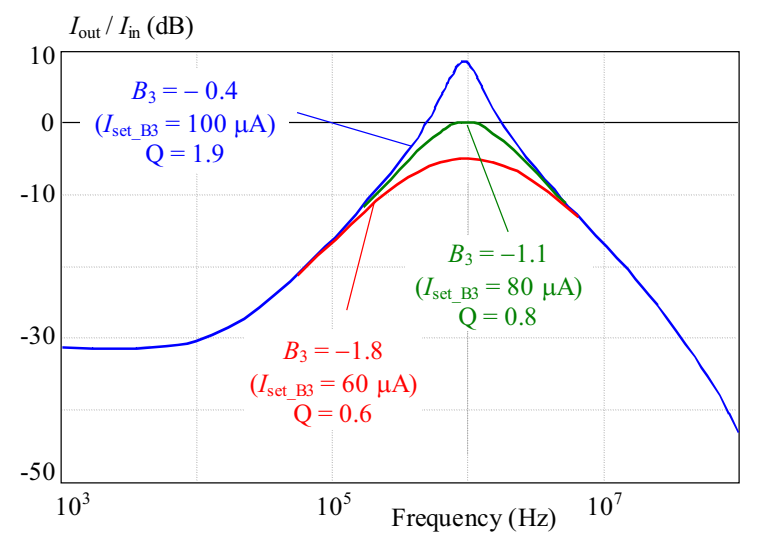

Fig. 15. Quality factor control: magnitude response of iBP for three different values of gain $B_{3}$ when $B_{1}=1, B_{2}=-1$

required for BS filter (one of them is inverted) and three copies of input current are required for AP filter (one of them has to be also inverted).

Center (pole) frequency and quality factor can be expressed as follows

$$
\begin{aligned}
& f_{0}=\frac{1}{2 \pi} \sqrt{\frac{-B_{2} G_{1} g_{m}}{C_{1} C_{2}}}, \\
& Q=\frac{1}{B_{3}} \sqrt{\frac{-B_{2} g_{m} C_{2}}{G_{1} C_{1}}} .
\end{aligned}
$$

From the previous equations it is obvious that:

- $B_{1}$ can be used for control of gain (and phase) of each of filtering functions,

- $B_{2}$ can be used for control of center frequency of iBP function with constant bandwidth (BW),

- $B_{3}$ can be used for control of quality factor of every filtering function,

- $g_{m}=G_{1}$ can be used for control of center frequency while keeping $Q$ constant.

When parasitic resistance of $X$ port $(450 \Omega)$ is taken into account, parameters of filter and passive components are calculated as follows: 
$f_{C}=1 \mathrm{MHz}$ is starting pole frequency for $g_{m}=$ $690 \mu \mathrm{S}\left(I_{\text {set_gm }}=33 \mu \mathrm{A}\right)$ and $G_{1}=1 \mathrm{mS}, Q=0.707$ (Butterworth approximation) for $B_{3}=-1, C_{1}=155 \mathrm{pF}$, $C_{2}=78 \mathrm{pF}$. Some of simulation results are summarized in Figs. 11-16. The first figure, Fig. 11 shows overall filter response for starting parameters as mentioned before in case of LP, iBP, HP and BS function, Fig. 12 shows characteristics of AP filter in the same conditions. Figs. 1316 present possibilities of control in case of iBP response. Figure 13 includes gain control, Fig. 14 shows control of center frequency with constant bandwidth, Fig. 15 control of quality factor with constant center frequency and finally, Fig. 16, tuning of center frequency with constant value of quality factor.

\section{CONCLUSION}

Presented filtering solution has many advantages thank to electronic control of four parameters: $g_{m}$ and of three independent current gains, therefore four parameters are controllable mutually independently as described briefly in Section 3. Filter consists of one active element and three passive elements, but $G_{1}$ could be omitted if control of pole frequency independently on quality factor and some of filtering functions is not required. From Figs. 1116 it is obvious that there are some parasitic influences, for example in case of HP response (Fig. 11), pass-band gain is not unity $(0 \mathrm{~dB})$. In this particular case it is caused by $R_{X}$ of $X$ terminal that acts as current divider with $G_{1}$. Note that this is not a problem, because gain could be fine-tuned by $B_{1}$ without affecting any other parameter of the filter. The same method could be used to finetune gain in case of quality factor adjustment (Fig. 15). All control processes were presented only on band pass response but tuning is also possible in case of other filtering functions. The main advantages of final filtering solution are

- all parameters of the filter are adjustable independently and electronically,

- not many active and passive elements are required,

- all passive elements are grounded and no output is taken from passive element and therefore additional buffering is not required,

- absorption of parasitic input resistance $\left(R_{X}\right)$ is possible, its expected values have been taken into calculations.

\section{Acknowledgement}

This research work was supported by Czech Science Foundation project 14-24186P, Czech Republic, and by projects SIX CZ.1.05/2.1.00/03.0072, EU ECOP EE.2.3.20.0094 and CZ.1.07/2.2.00/28.0062. The support of the project CZ.1.07/2.3.00/20.0007 WICOMT, financed from the operational program Education for competitiveness, is gratefully acknowledged.

\section{REFERENCES}

[1] BIOLEK, D.-SENANI, R.-BIOLKOVA, V.-KOLKA, Z. : Active Elements for Analog Signal Processing: Classification, Review and New Proposals, Radioengineering 17 No. 4 (2008), $15-32$.

[2] KESKIN, A. U.-BIOLEK, D.-HANCIOGLU, E.-BIOLKOVA, V.: Current-mode KHN filter employing Current Differencing Transconductance Amplifiers, International Journal of Electronics and Communications (AEU) 60 No. 6 (2006), 443-446.

[3] JAIKLA, W.-LAHIRI, A. : Resistor-Less Current-Mode FourPhase Quadrature Oscillator using CCCDTAs and Grounded Capacitors, AEU - International Journal of Electronics and Communications 66 No. 3 (2011), 214-218.

[4] SAKUL, C.-JAIKLA, W.-DEJHAN, K.: New Resistorless Current-Mode Quadrature Oscillators Using 2 CCCDTAs and Grounded Capacitors, Radioengineering 20 No. 4 (2011), 890-896.

[5] GEIGER, R. L.-SÁNCHEZ-SINENCIO, E. : Active Filter Design using Operational Transconductance Amplifiers: a Tutorial, IEEE Circ. and Devices Magazine 1 (1985), 20-32.

[6] FABRE, A.-SAAID, O.-WIEST, F.-BOUCHERON, C. : High Frequency Applications based on a New Current Controlled Conveyor, IEEE Trans. on Circuits and Systems - I 43 No. 2 (1996), 82-91.

[7] SEDRA, A.-SMITH, K. C.: A Second Generation Current Conveyor and its Applications, IEEE Transaction on Circuit Theory CT-17 No. 2 (1970), 132-134.

[8] PROKOP, R.-MUSIL, V.: Modular Approach to Design of Modern Circuit Blocks for Current Signal Processing and New Device CCTA, in Proc. Conf. on Signal and Image Processing IASTED, Anaheim, 2005, pp. 494-499.

[9] SIRIPRUCHYANUN, M.-JAIKLA, W.: Current Controlled Current Conveyor Transconductance Amplifier (CCCCTA): a Building Block for Analog Signal Processing, Electrical Engineering Springer 90 No. 6 (2008), 443-453.

[10] SOTNER, R.-JERABEK, J.-PROKOP, R.-VRBA, K. : Current Gain Controlled CCTA and its Application in Quadrature Oscillator and Direct Frequency Modulator, Radioengineering 20 No. 1 (2011), 317-326.

[11] SURAKAMPONTORN, W.-THITIMAJSHIMA, W.: Integrable Electronically Tunable Current Conveyors, IEE Proceedings-G, 135 No. 2 (1988), 71-77.

[12] FABRE, A.-MIMECHE, N. : Class A/AB Second-Generation Current Conveyor with Controlled Current Gain, Electronics Letters 30 No. 16 (1994), 1267-1268.

[13] BIOLEK, D.-LAHIRI, A.-JAIKLA, W.-SIRIPRUCHYANUN, M.-BAJER, J.: Realisation of Electronically Tunable Voltage-Mode/Current-Mode Quadrature Sinusoidal Oscillator using ZC-CG-CDBA, Microelectronics Journal 42 No. 10 (2011), 1116-1123.

[14] ALZAHER, H.-TASADDUQ, N.-ASMALLL-EES, O.-AlAMMARI, F. : A Complementary Metal-Oxide Semiconductor Digitally Programmable Current Conveyor, International Journal of Circuit Theory and Applications 41 No. 1 (2013), 69-81.

[15] TANGSRIRAT, W.: Electronically Tunable Multi-Terminal Floating Nullor and its Application, Radioengineering 17 No. 4 (2008), 3-7.

[16] TANGSRIRAT, W.-PUKKAlanun, T.: Digitally Programmable Current Follower and its Applications, AEU - International Journal of Electronics and Communications 63 No. 5 (2009), 416-422.

17] SOULITIS, G.-PSYCHALINOS, C.: Electronically Controlled Multiphase Sinusoidal Oscillators using Current Amplifiers, International Journal of Circuit Theory and Applications 37 No. 1 (2009), 43-52.

[18] JERABEK, J.-VRBA, K.: Fully Differential Universal Filter with Differential and Adjustable Current Followers and 
Transconductance Amplifiers, In Proceeding of the 33rd International Conference on Telecommunications and Signal Processing - TSP 2010 (2010), 5-9, Baden, Austria.

[19] JERABEK, J.-SOTNER, R.-VRBA, K. : Fully-Differential Current Amplifier and its Application to Universal and Adjustable Filter, 2010 International Conference on Applied Electronics. Pilsen: University of West Bohemia, 2010. pp. 141-144..

[20] SOTNER, R.-JERABEK, J.-HERENCSAR, N.-HRUBOS, Z.-DOSTAL, T.-VRBA, K. : "Study of Adjustable Gains for Control of Oscillation Frequency and Oscillation Condition in 3R-2C Oscillator, Radioengineering 21 No. 1 (2012), 392-402.

[21] JERABEK, J.-KOTON, J.-SOTNER, R.-VRBA, K. : Adjustable Band-Pass Filter with Current Active Elements: Two Fully-Differential and Single-Ended Solutions, Analog Integrated Circuits and Signal Processing 74 No. 1 (2013), 129-139.

[22] SOTNER, R.-JERABEK, J.-SEVCIK, B.-DOSTAL, T.VRBA, K.: Novel Solution of Notch/All-Pass Filter with Special Electronic Adjusting of Attenuation in the Stop Band, Elektronika i Elektrotechnika 17 No. 7 (113) (2011), 37-42.

[23] CHUNHUA, W.-KESKIN, A. U.-YANG, L.-QIUJING, Z.-SICHUN, D.: Minumum Configuration Insensitive Multifunctional Current-Mode Biquad using Current Conveyors and All-Grounded Passive Components, Radioengineering 19 No. 1 (2010), 178-184.

[24] TANGSRIRAT, W.-UNHAVANICH, S.-DUMAWIPATA, T.-SURAKAMPONTORN, W. : Single-Input and Three- Output Current-Mode Biquadratic Filters using Multiple-Output OMAs, The Journal of KMITNB 13 No. 2 (2003).

[25] CHAUHAN, C.-TOMAR, R.-SINGH, S. V.-CHAUHAN, D. S.: Current Controlled Current-Mode SITO Biquad Universal Filter Using CCTAs, In Proc. Conference on Advances in Communication and Control Systems 2013 (CAC2S 2013), Dehradun, pp. 297-301

[26] AYTEN, U. E.-SAGBAS, M.: Current-Mode SITO Filter using a Single Active Component, In Proc. European Conference on Circuit Theory and Design, 2009, pp. 133-136.

[27] SENANI, R.-GUPTA, S. S. : Current-Mode Universal Biquad using Current Followers: A Minimal Realization, Radioengineering 20 No. 4 (2011), 898-904.

[28] TANGSRIRAT, W.-BUnRUANG, K. : Current-Mode Universal Filter Topology with Electronic Tuning Property using Single Current Follower, Indian Journal of Pure \& Applied Physics 50 (Feb 2012), 133-137.
[29] SHAH, N. A.-RATHER, M. F.-IQBAL, S. Z.: SITO Electronically Tunable High Output Impedance Current-Mode Universal Filter, Analog Integrated Circuits and Signal Processing 47 (2006), 335-338.

30] SURAKAMPONTORN, W.-KUMWACHARA, K. : CMOSBased Electronically Tunable Current Conveyor, Electronics Letters 28 No. 14 (1992), 1316-1317.

31] MOSIS parametric test results of TSMC LO EPI SCN018 technology, [ftp://ftp.isi.edu/pub/mosis/vendors/tsmc-018/t44e lo epi-params.txt]. Cited 24.7.2013.

Received 6 January 2014

Jan Jerabek was born in Bruntál, Czech Republic, in 1982. He received the $\mathrm{PhD}$ degree in Electrical Engineering in 2011 from the Brno University of Technology, Czech Republic. He received MSc and BSc degree from the same university in 2007 and 2005, respectively. He is currently an Assistant Professor at the Department of Telecommunications, Faculty of Electrical Engineering and Communication, Brno University of Technology. His research interests are focused on circuit applications of modern active elements such as current amplifiers and multiple output current followers.

Roman Sotner was born in Znojmo, Czech Republic, in 1983. He received the $\mathrm{MSc}$ and $\mathrm{PhD}$ degrees from the Brno University of Technology, Czech Republic, in 2008 and 2012, respectively. Currently, he is a technical worker at the Department of Radio Electronics, Faculty of Electrical Engineering and Communication, Brno University of Technology, Brno, Czech Republic. His interests are analog circuits (active filters, oscillators, audio, etc), circuits in the current mode, circuits with direct electronic controlling possibilities especially and computer simulation.

Kamil Vrba received the $\mathrm{PhD}$ degree in Electrical Engineering in 1976, and the Prof degree in 1997, both from the Brno University of Technology. Since 1990 he has been Head of the Department of Telecommunications of the Faculty of Electrical Engineering and Communication of Brno University of Technology. His research work is concentrated on problems concerned with the accuracy of analog circuits and mutual conversion of analog and digital signals.

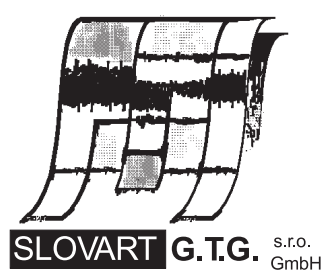

EXPORT - IMPORT
EXPORT - I M P OR T

of periodicals and of non-periodically printed matters, books and CD-ROMs

Krupinská 4 PO BOX 152, 85299 Bratislava 5, Slovakia tel: ++421 263839 472-3, fax: ++421263839485 info@slovart-gtg.sk; http://www.slovart-gtg.sk

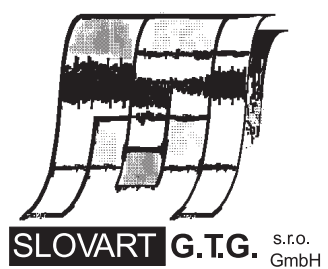

EXPORT - IMPORT 